九州大学学術情報リポジトリ

Kyushu University Institutional Repository

\title{
Chloroplastic Glucose 6-Phosphate Dehydrogenase from Chlorella vulgaris Alleviates Freezing and Menadione-Induced 0xidative Stresses in Saccharomyces cerevisiae
}

Machida, Takeshi

Laboratory of Food Hygienic Chemistry, Division of Food Biotechnology, Department of

Bioscience and Biotechnology, Faculty of Agriculture, Graduate School, Kyushu University

Ohashi, Naoto

Laboratory of Food Hygienic Chemistry, Division of Food Biotechnology, Department of Bioscience and Biotechnology, Graduate School of Bioresource and Bioenvironmental Sciences, Kyushu University

Mimura, Ayano

Laboratory of Food Hygienic Chemistry, Division of Food Biotechnology, Department of Bioscience and Biotechnology, Graduate School of Bioresource and Bioenvironmental Sciences, Kyushu University

Honjo, Ken-ichi

Laboratory of Food Hygienic Chemistry, Division of Food Biotechnology, Department of

Bioscience and Biotechnology, Faculty of Agriculture, Graduate School, Kyushu University

他

https://doi.org/10.5109/17797

出版情報: 九州大学大学院農学研究院紀要. 55 (1)，pp.29-38，2010-02-26. Faculty of Agriculture， Kyushu University

バージョン :

権利関係 : 


\title{
Chloroplastic Glucose 6-Phosphate Dehydrogenase from Chlorella vulgaris Alleviates Freezing and Menadione-Induced Oxidative Stresses in Saccharomyces cerevisiae
}

\author{
Takeshi MACHIDA, Naoto OHASHI ${ }^{1}$, Ayano MIMURA ${ }^{1}$, Ken-ichi HONJOH*, \\ Masayoshi IIO and Takahisa MIYAMOTO
}

\author{
Laboratory of Food Hygienic Chemistry, Division of Food Biotechnology, \\ Department of Bioscience and Biotechnology, Faculty of Agriculture, \\ Graduate School, Kyushu University, Fukuoka 812-8581, Japan \\ (Received October 29, 2009 and accepted November 19, 2009)
}

\begin{abstract}
Enhanced glucose 6-phosphate dehydrogenase (E.C.1.1.1.49, G6PDH) activity has been identified as a hardening-induced intracellular change of Chlorella vulgaris, which acquires freezing tolerance during hardening. In the present study, a full-length cDNA clone corresponding to a gene encoding a chloroplastic isoform of $\mathrm{G} 6 \mathrm{PDH}$, designated CvchG6PDH, was isolated from C. vulgaris $\mathrm{C}-27$. By comparing the deduced amino acid sequence of $C v c h G 6 P D H$ with the N-terminal amino acid sequence of mature $\mathrm{G}_{6} \mathrm{PDH}_{2}$ protein isolated previously, a DNA region encoding mature CvchG6PDH was determined and designated $m C v c h G 6 P D H$. The deduced amino acid sequence of $C v c h G 6 P D H$ showed higher homology to those of plant plastidic $G 6 P D H$ genes than those of cytosolic ones. A recombinant mCvchG6PDH protein expressed in Escherichia coli showed similar enzymatic properties to previously-isolated Chlorella $\mathrm{G}_{6} \mathrm{PDH}_{2}$, suggesting that the gene encoded plastidic $\mathrm{G}_{6} \mathrm{PDH}_{2}$ protein. Expression of $\mathrm{CvchG6PDH}$ was induced transcriptionally throughout 24-h hardening, while the translation was induced up to 9-h hardening and then decreased, and the change did not reflect the enhanced G6PDH activity during hardening. Furthermore, the mCvchG6PDH alleviated both freezing and menadione-induced oxidative stresses in yeast. We showed the contribution of $C v c h G 6 P D H$ in menadione stress tolerance as one of its functions in the acquisition of freezing tolerance of Chlorella.
\end{abstract}

\section{INTRODUCTION}

Freezing injury is one of the most severe constraints limiting plant growth and it has been a major preoccupation in northern latitude (Levitt, 1980). It could be said that to investigate the developing mechanisms of plants against freezing is very important for the purpose of stable food production and establishment of the method for long-term food storage. Some plants acquire freezing tolerance when exposed to non-freezing low temperatures, and their physiological strategies used to tolerate freezing stress vary (Sadakane et al., 1980; Sarhan and Perras, 1987; Thomashow, 1990; Uemura et al., 1997).

We have studied the acquisition of freezing tolerance of plants, using Chlorella vulgaris $\mathrm{C}-27$ as a convenient eukaryotic model. Hardened cells of $C$. vulgaris C-27 can survive after freezing treatment even at $-196{ }^{\circ} \mathrm{C}$ (Hatano et al., 1976). In our previous studies, we have found an increase in the activity of glucose 6-phosphate dehydrogenase (G6PDH) as an intracellular change of Chlorella during hardening (Sadakane et al., 1980). The enzyme, G6PDH (EC 1.1.1.49), catalyses the ratelimiting step of the oxidative pentose phosphate pathway (OPPP), an important catabolic route for the provision of NADPH and sugar phosphates (Wendt et al., 2000). In plants, G6PDH isoenzymes reside in two com-

\footnotetext{
${ }^{1}$ Laboratory of Food Hygienic Chemistry, Division of Food Biotechnology, Department of Bioscience and Biotechnology, Graduate School of Bioresource and Bioenvironmental Sciences, Kyushu University

* Corresponding author (E-mail: honjoh@agr.kyushu-u.ac.jp)
}

partments, cytosol and plastids (Schnarrenberger et al., 1973). The plastidic G6PDH is known to be reductively inactivated, achieved via reversible dithiol-disulphide interchange of two highly conserved regulatory cysteine residues specific to the plastidic one (Wenderoth et al., 1997). The main role of G6PDH in plastids is the supply of reducing equivalents in the form of NADPH required for various reductive biosyntheses (e.g. amino acids, fatty acids) and to provide sugar-phosphate intermediates that serve as precursors of nucleotides and secondary plant products. In plants, substantial evidences show that G6PDH might be involved in responses to stresses, such as oxidative stress (Hauschild and von Schaewen, 2003; Debnam et al., 2004) and salt stress (Nemoto and Sasakuma, 2000).

A number of factors have appeared to be involved in freezing injury of plants, including water deficit due to ice formation, lipid phase separation, and inactivation of ATPase in plasma membrane (Tao et al., 1998). In addition, production of reactive oxygen species (ROS) during freezing-thawing may be involved. In research on coniferous plant, increases in superoxide dismutase activity and ascorbate content have been found when suffering photooxidative damage in fall and winter (Tao et al., 1990; 1992). Many researchers have studied the relationship between ROS-scavengers and freezing tolerance, and clarified the importance and the role in the acquisition of freezing tolerance (Seppanen and Fagerstedt, 2000; Kocsy et al., 2001; Yang et al., 2007). Those reports suggest that protection system against ROSmediating oxidative damage plays an important role in improvement of freezing tolerance of plants. 
We have previously purified and characterized two isoforms of G6PDHs from Chlorella. The two G6PDHs appeared to be the cytosolic and the chloroplastic enzymes based on their sensitivities to DTT (Honjoh et al., 2003). Furthermore, we have isolated and characterized a cDNA encoding cytosolic G6PDH, and investigated the involvement in the acquisition of freezing tolerance using transformed yeast (Honjoh et al., 2007). Although the gene encoding cytosolic G6PDH, designated $C v c G 6 P D H$, was induced at a transcriptional level during hardening, leading to the change in the activity, it did not reflect the increase in the activity of G6PDH during hardening. The previous study also showed that the freeze-thaw stress tolerance of the transformed yeast expressing $C v c G 6 P D H$ was not improved sufficiently in spite of the 8.7-fold high activity of G6PDH compared to that of the control strain. Thus, involvement of other isoform in freezing tolerance should be investigated.

In the present study, we have isolated and characterized a cDNA for chloroplastic $G 6 P D H$ gene from $C$. vulgaris $\mathrm{C}-27$. The effect of low temperatures, responsible for the freezing tolerance of Chlorella, on the expression of the gene was investigated at transcriptional and post-transcriptional levels. Furthermore, the involvements of two isotypes of Chlorella G6PDH in the acquisition of stress tolerance were investigated using transformed yeast expressing the gene.

\section{MATERIALS AND METHODS}

\section{Strains and conditions}

Chlorella vulgaris Beijerinck IAM C-27 was obtained from the Algal Culture Collection of the Institute of Applied Microbiology, Tokyo University, Japan. Cells of C. vulgaris $\mathrm{C}-27$ were cultured at $25^{\circ} \mathrm{C}$ synchronously and hardened at $3{ }^{\circ} \mathrm{C}$ as described previously (Honjoh et al., 2007).

Escherichia coli BL21(DE3)pLysS (Novagen, Madison, WI, USA) was used for production of a large amount of recombinant mCvchG6PDH protein in E. coli.

Saccharomyces cerevisiae INVSc2 (Mat $\alpha$, his3 4200, ura3-167; Invitrogen, Carlsbad, CA, USA) was used for expression of $m C v c h G 6 P D H$ in yeast.

\section{Isolation of a full-length cDNA clone encoding CvchG6PDH and sequence analysis}

Hardened cells of Chlorella were harvested, washed twice with sterilized water, and suspended in an extraction buffer, which contained 0.1 M Tris-HCl ( $\mathrm{pH} 7.0$ ), $0.1 \mathrm{M} \mathrm{NaCl}, 10 \mathrm{mM}$ EDTA, and 0.1\% SDS, dissolved in diethylpyrocarbonate-treated water. Purification of poly(A) + RNA and cDNA synthesis were performed based on the method of Machida et al. (2009). A partial CvchG6PDH cDNA fragment was amplified using two degenerated primers, 5'- GAT GCT TTT A(C/T)C ATT C(C/G/T)G GTC AGT A(C/T)A A -3' and 5'- CTC (C/T) TT (A/G)CC CA(A/G) GTA (A/G)TG GTC (A/G)AT -3', designed based on conserved regions of G6PDHs. DNA regions that extended 5'- and 3'-ends of the full-length CvchG6PDH cDNA were amplified using rapid amplifi- cation of cDNA ends (RACE) method. Full-length CvchG6PDH cDNA was amplified with two primers, 5'GGC CCT TTT CGT TGT TGA GCC TG -3' and 5'- CCA GGC AAC AGC AAT TAC AGG GGA -3'. Amplified fragments were subcloned into a pGEM-T easy vector (Promega, Madison, WI, USA), and nucleotide sequences of the fragments were determined based on the method of Sanger et al. (1977).

Homologous genes to the $C v c h G 6 P D H$ were searched for using the tBlastX program (Altschul et al., 1990) on the National Center of Biotechnology Information web site (http://www.ncbi.nlm.nih.gov/), and the identity (\%) was calculated using the clustal W program (http://align. genome.jp/). Phylogenetic tree was constructed with the Neighbor-Joining method based on the method of Wendt et al. (1999). Subcellular localization of the protein encoded by the cloned cDNA was predicted using the WoLF PSORT program (Houton et al., 2006).

\section{Northern blot analysis}

Total RNAs from unhardened, 3, 9, and 24-h hardened cells were isolated as described above. Ten micrograms of total RNA were separated on a 1.0\% agarose gel containing $1.8 \%$ formaldehyde, and blotted onto a Hybond- $\mathrm{N}^{+}$nylon membrane (GE healthcare, Heidelberg, Germany). The membrane was subjected to Northern blot analysis using a DIG High Prime DNA Labeling and Detection Starter Kit II (Roche, Basel, Switzerland). The full-length $C v c h G 6 P D H$ cDNA was labeled by the random-labeling method with DIG-dUTP, and then used as a probe. The hybridized bands were detected using a chemiluminescent substrate, [3-(5-Chloro-4'methoxyspiro[adamantane-2,3'-[1,2]dioxetan]-4'-yl) phenyl] phosphate phosphoric acid 3-[4'-methoxy-5chlorospiro [tricyclo[3.3.1.1 $1^{3,7}$ ]decane-2,3'-[1,2]dioxetane] -4 '-yl]phenyl ester, supplied in the kit. The loading amount of total RNA was standardized by comparison with the electrophoretic band intensity of rRNA.

\section{Expression of mCvchG6PDH in $E$. coli}

A gene encoding a mature form of CvchG6PDH, designated $m C v c h G 6 P D H$, was amplified by PCR using the full-length cDNA as a template. To amplify mCvch$G 6 P D H$, two primers with the recognition sites of NheI and XhoI were designed (5'- TAT GCT AGC GGG TTG CAA GAG GAG AAC TGG -3' and 5'- GGC CTC GAG TCA CTC GTC GTC AGC G-3'; recognition sites of NheI and $X h o I$ are underlined). The amplified DNA fragment was digested with the corresponding enzymes and ligated into the NheI-XhoI site of a pET-17xb vector (Novagen). E. coli BL21(DE3)pLysS was transformed with the plasmid by the electroporation method according to the manufacturer's instructions (BTX Division of Genetronics, Inc., Holliston, MA, USA). The transformants were selected by cultivation on LB/Amp/Cam agar containing ampicillin $(100 \mu \mathrm{g} / \mathrm{ml})$ and chloramphenicol $(34 \mu \mathrm{g} / \mathrm{ml})$ at $37^{\circ} \mathrm{C}$ for $16 \mathrm{~h}$.

The $m C v c h G 6 P D H$ was separately amplified by PCR to be ligated into a pET-32a(+) vector (Novagen) with two primers, 5'- TAT GGA TCC GGG TTG CAA GAG GAG 
AAC TGG -3' and 5'- CGG CGT CGA CTC ACT CGT CGT CAG CG -3'containing BamHI and SalI recognition sites (underlined). The amplified DNA fragment was digested and incorporated into the BamHI-SalI site of the vector. The plasmid generated was introduced into E. coli BL21(DE3)pLysS by the electroporation method. The transformants were selected by cultivation on LB/ Amp/Cam agar plates at $37^{\circ} \mathrm{C}$ for $16 \mathrm{~h}$.

\section{Expression of $m C v c h G 6 P D H$ in $E$. coli and purifi- cation of His-tagged mCvchG6PDH protein}

The $E$. coli transformants were cultured in LB/Amp/ Cam medium at $37^{\circ} \mathrm{C}$ with shaking. When the $\mathrm{OD}_{600}$ reached 0.5, isopropyl- $\beta$-D-thiogalactopyranoside (IPTG) was added to the culture at a final concentration of $1 \mathrm{mM}$. After $6 \mathrm{~h}$ of cultivation at $25^{\circ} \mathrm{C}$, the cells were collected by centrifugation, then resuspended in $50 \mathrm{mM}$ potassium-phosphate buffer ( $\mathrm{pH} 7.5 ; \mathrm{K}-\mathrm{Pi}$ ) containing $1 \mathrm{mM}$ phenylmethylsulfofluoride (PMSF), and disrupted at $4{ }^{\circ} \mathrm{C}$ by sonication using a Tomy Ultrasonic Disrupter UP-201 (Tomy Seiko, Tokyo, Japan) for 10 min at $48 \mathrm{~W}$ with $0.5-\mathrm{s}$ pulses at $0.5-\mathrm{s}$ intervals. The suspension was centrifuged at $20,000 \times g$ for $10 \mathrm{~min}$ at $4{ }^{\circ} \mathrm{C}$ and the resulting supernatant was used for further experiments. His-tagged mCvchG6PDH was purified by $\mathrm{Ni}^{2+}$-affinity chromatography using a His $\cdot$ Bind resin (Novagen) according to the manufacturer's instructions. Expression and purification of the proteins were checked by SDSPAGE on a $10 \%$ polyacrylamide gel by the method of Laemmli (1970).

\section{Preparative SDS-PAGE and N-terminal amino acid sequencing}

The partially-purified His-tagged mCvchG6PDH protein was treated with enterokinase at $23^{\circ} \mathrm{C}$ for $16 \mathrm{~h}$ or thrombin (Novagen) at $25^{\circ} \mathrm{C}$ for $16 \mathrm{~h}$ to remove tagging peptides. And then, the digested proteins were purified additionally by preparative electrophoresis. The purified mCvchG6PDH was subjected to SDS-PAGE and electroblotted onto a polyvinylidene difluoride membrane (Towbin et al., 1970). The N-terminal sequence of the detected protein was analyzed with a gas-phase protein sequence analyzer (model PPSQ-21; Shimadzu, Kyoto, Japan). Rabbit anti-mCvchG6PDH polyclonal antibodies were raised using the purified mCvchG6PDH as an antigen.

\section{Enzyme assays}

G6PDH activity was assayed in a double-beam mode using a Shimadzu UV-visible recording spectrophortometer (Shimadzu) as described previously (Honjoh et al., 2003). The assay mixture contained $55 \mathrm{mM}$ Tris- $\mathrm{HCl}$ ( $\mathrm{pH} 7.8$ ), $3.3 \mathrm{mM} \mathrm{MgCl}_{2}, 0.2 \mathrm{mM} \mathrm{NADP}{ }^{+}, 3.3 \mathrm{mM}$ glucose 6-phosphate, and protein extract. One unit of activity was defined as the amount of enzyme forming $1.0 \mu \mathrm{mol}$ of NADPH per minute at $25^{\circ} \mathrm{C}$.

Dithiothreitol (DTT)-sensitivity test was performed as follows. Protein samples were incubated on ice for $3 \mathrm{~h}$ in the presence of $100 \mathrm{mM}$ DTT. Residual activity (\%) was expressed as the percentage of specific activity of treated sample against that of untreated sample.

\section{Protein extraction from Chlorella}

Chlorella cells were harvested, washed twice, and suspended in $50 \mathrm{mM} \mathrm{K-Pi} \mathrm{containing} 1 \mathrm{mM}$ PMSF. The suspension was frozen in liquid nitrogen and stored at $-80{ }^{\circ} \mathrm{C}$ until use. The frozen suspension of cells was thawed at $4^{\circ} \mathrm{C}$ and homogenized with $0.5 \mathrm{~mm}$ diameter glass beads on a reciprocal shaker (Vibrogen-Zellmühle, Edmund Bühler Co., Tübingen, Germany), operated at 4,500 rpm at $4{ }^{\circ} \mathrm{C}$ for $20 \mathrm{~min}$. The homogenate was freed from the beads by passage through a sintered-glass funnel and then centrifuged at 20,000 $\times g$ for $30 \mathrm{~min}$ at $4{ }^{\circ} \mathrm{C}$. The upper phase was recovered and centrifuged again at $20,000 \times g$ for $60 \mathrm{~min}$ at $4{ }^{\circ} \mathrm{C}$. The resulting upper phase was used in further experiments as a Chlorella cell extract.

\section{Western blot analysis}

Protein extracts of unhardened, 3, 9, and 24-h hardened Chlorella cells were separated by SDS-PAGE, and then electroblotted onto a nitrocellulose membrane. The membrane was blocked with 3\% skimmed milk in TBS containing $0.1 \%$ Tween-20 (TTBS) for $1 \mathrm{~h}$, incubated with antibodies for CvchG6PDH at a 1:500 (v/v) dilution in TTBS containing 3\% skimmed milk for $1 \mathrm{~h}$, washed four times with TTBS, and then incubated with anti-rabbit IgG (whole molecule)-peroxidase (Sigma-aldrich, St. Louis, MO, USA) at a 1:500 (v/v) dilution in TTBS containing 3\% skimmed milk for $1 \mathrm{~h}$. After washing the membrane four times with TTBS, bands were detected with 3,3'-diaminobenzidine tetrahydrochloride and hydrogen peroxide. All procedures in this section were performed at room temperature.

\section{Quantification of band intensity}

The bands shown in the results of Northern blot and Western blot were quantified using the Yab's Gel Image software (http://homepage.mac.com/yabyab/rb/gelimagej.html).

\section{Plasmid construction and transformation of yeast}

To express the $m C v c h G 6 P D H$ genes in $S$. cerevisiae, the $m C v c h G 6 P D H$ was amplified by PCR using Phusion DNA polymerase (Finnzymes, Keilaranta, Finland). To amplify $m C v c h G 6 P D H$, two oligonucleotides with the recognition sites of $B g l I$ II and EcoRI were designed (5'TAT AGA TCT ATG GGG TTG CAA GAG GAG AAC -3' and 5'- CGG CGA ATT CTC ACT CGT CGT CAG CGG -3'; recognition sites of $B g l$ II and EcoRI are underlined). The amplified DNA fragment was digested with the corresponding enzymes and introduced into the $B g l \amalg-E c o R I$ site of a pTG887 vector (Transgene S. A., France), downstream of the $P G K$ promoter to allow a high level of expression of introduced genes. The plasmid generated was designated pTG887/mCvchG6PDH.

S. cerevisiae INVSc2 was transformed with the plasmids by the lithium acetate method (Ito et al., 1983). Transformants were screened onto an uracil-deficient synthetic raffinose (SR-ura) agar plate, which contained 
$0.67 \%$ yeast nitrogen base, $2 \%$ raffinose, $0.2 \%$ complete supplement mixture without uracil (CSM-URA, BIO 101, Vista, CA, USA), and $2 \%$ agar, at $30^{\circ} \mathrm{C}$ for $48 \mathrm{~h}$.

\section{Expression of the introduced genes in yeast}

The transformed yeast cells were cultured overnight in SR-ura medium with shaking at $30^{\circ} \mathrm{C}$. The overnight cultures were inoculated into SR-ura containing $2 \%$ glucose to express the introduced genes. After $24 \mathrm{~h}$ of cultivation at $30^{\circ} \mathrm{C}$, the yeast cells were harvested by centrifugation at $1,000 \times g$ for $10 \mathrm{~min}$, and suspended in $10 \mathrm{mM}$ Tris-HCl (pH 7.5) containing $1 \mathrm{mM}$ PMSF. The cell suspension was mixed with an equal volume of $0.5 \mathrm{~mm}$ diameter glass beads and homogenized with a vortex mixer. The homogenates were centrifuged at $20,000 \times g$ at $4{ }^{\circ} \mathrm{C}$ for $10 \mathrm{~min}$. G6PDH activity in yeast was determined using the soluble lysate by the method described above.

\section{Freezing tolerance test}

Yeast cells expressing $m C v c h G 6 P D H$ were pre-cultured in $2 \mathrm{ml}$ of SR-ura medium with shaking at $30^{\circ} \mathrm{C}$ for $48 \mathrm{~h}$. Five microliters of pre-cultured cells were inoculated into $5 \mathrm{ml}$ of SR-ura medium containing $2 \%$ glucose. When the $\mathrm{OD}_{600}$ reached 1.0, the yeast cells were harvested by centrifugation at $560 \times g$ for $5 \mathrm{~min}$ at room temperature, and resuspended in a $0.9 \% \mathrm{NaCl}$ solution at a cell concentration of $2-3 \times 10^{6}$ cells $/ \mathrm{ml}\left(\mathrm{OD}_{600}=0.1\right)$. One hundred microliters of the cell suspensions were transferred to 1.5-ml microcentrifuge tubes and prechilled in a deep-freezer at $-80{ }^{\circ} \mathrm{C}$ for 2 min for ice formation. Then, the samples were subjected to freezing treatment in a program freezer at $-20^{\circ} \mathrm{C}$ for $24 \mathrm{~h}$. After freezing treatment, the samples were thawed at $25^{\circ} \mathrm{C}$, serially diluted with $0.9 \% \mathrm{NaCl}$, and immediately plated onto YPD agar plates, containing 1\% yeast extract, $2 \%$ polypeptone, $2 \%$ glucose, and $1.5 \%$ agar. After $2 \mathrm{~d}$ of incubation at $30^{\circ} \mathrm{C}$, colonies were counted. Viability (\%) was calculated by dividing the counts of frozen sample by those of unfrozen one. Yeast cells carrying pTG887 and pTG887/CvcG6PDH (Honjoh et al., 2007) were also tested.

\section{Oxidative stress tolerance test}

The pre-cultured transformants were inoculated into $5 \mathrm{ml}$ of SR-ura medium containing $2 \%$ glucose, and cultured at $30{ }^{\circ} \mathrm{C}$ with shaking until $\mathrm{OD}_{600}$ reached 0.5 . Then, the cells were harvested by centrifugation at 560 $\times g$ for 5 min at room temperature, washed twice with $100 \mathrm{mM}$ sodium-phosphate buffer ( $\mathrm{pH} 7.0, \mathrm{Na}-\mathrm{Pi}$ ), and resuspended in $\mathrm{Na}-\mathrm{Pi}$ at a cell concentration of $2-3 \times$ $10^{6}$ cells $/ \mathrm{ml}\left(\mathrm{OD}_{600}=0.1\right)$. One milliliter of the cell suspensions was mixed with menadione, which induces production of superoxide anion inside the cells, at a final concentration of $200 \mu \mathrm{M}$ and then incubated at $30^{\circ} \mathrm{C}$ for $1 \mathrm{~h}$ with shaking. After stress treatment, the samples were serially diluted with $\mathrm{Na}-\mathrm{Pi}$ and immediately plated onto YPD agar plates. After $2 \mathrm{~d}$ of incubation at $30^{\circ} \mathrm{C}$, the colonies were counted. Viability (\%) was calculated by dividing the counts of frozen sample by those of unfro- zen one. Yeast cells carrying pTG887 and pTG887/ $C v c G 6 P D H$ were also tested.

\section{Statistical analysis}

Statistical analysis was performed using Excel 2004 (Microsoft, USA) with the add-in software Statcel 2 (Yanai, 2002). The Tukey-Kramer test was used to evaluate significance among the groups by one-way ANOVA.

\section{RESULTS}

\section{Isolation of full-length cDNA encoding CvchG6PDH}

A 309 bp CvchG6PDH DNA fragment was amplified by PCR using degenerated primers. Nucleotide sequence of a full-length cDNA clone of Cvch G6PDH gene was determined using 5'- and 3'-RACE procedures based on the sequence of the 309-bp fragment. The full-length cDNA fragment was amplfied by PCR, subcloned into a pGEM-T easy vector, and sequenced. The length of CvchG6PDH was 2,397 bp in length and contained an open reading frame encoding 598 amino acid residues. A putative active region (-RIDHYLGKE-) and two coenzyme-binding sites (-GXXGXXG/A-) (Cosgrove et al., 1998) were found in the deduced amino acid sequence of CvchG6PDH (Fig. 1).

A computer search of the databases using the Clustal W program revealed that the deduced amino acid sequence of the obtained cDNA exhibited 58-59\% identity to those of the plastidic G6PDHs from higher plants and $41-44 \%$ identity to those of the cytosolic G6PDHs (Table 1). Phylogenetic analysis was performed to estimate the subcellular localization of $C v c h G 6 P D H$ based on the deduced amino acid sequence (Fig. 2). Moreover, the result of analysis using the WoLF PSORT program also indicated that the encoded protein is targeted or localized in the chloroplast. The $\mathrm{N}$-terminal $\left(\mathrm{NH}_{2}-\right.$ GLQEENWEKAALSIV-) and internal (-LVIRIQPNEGIYLKVNNKVP-) amino acid sequences of chloroplastic G6PDH protein $\left(\mathrm{G}_{6} \mathrm{PDH}_{2}\right.$, Honjoh et al., 2003) were found in the deduced amino acid sequence

Table 1. Sequence homology between the deduced amino acid sequence of CvchG6PDH and those of other cytosolic and plastidic G6PDH genes as given by Clustal W program

\begin{tabular}{ccc}
\hline \multicolumn{1}{c}{ Origin } & Identity (\%) & Accession number \\
\hline Plastidic G6PDH & & \\
Solanum tuberosum & 58.9 & AJ010712 \\
Dunaliella bioculata & 58.6 & AJ132346 \\
Arabidopsis thaliana & 58.5 & AJ001359 \\
Nicotiana tabacum & 58.5 & AJ001772 \\
Spinacia oleacea & 57.6 & AJ000182 \\
Petroselinum crispum & 56.5 & AF012861 \\
Cytosolic G6PDH & & \\
A. thaliana & 43.9 & AJ010971 \\
S. tuberosum & 43.4 & X74421 \\
N. tabacum & 43.4 & AJ001770 \\
Oryza sativa & 42.8 & AY078072 \\
Chlorella vulgaris & 40.9 & AB085846 \\
\hline
\end{tabular}


91 TTGAGCAGCGATCGGGGCGCGCAGCAGGCCGACCCGTGATGCCCGCTCTGCACAGCATGAGGCTCGTTGCACAAGTTCTGACCCTCAGCC $\begin{array}{llllllllllllllllllllll}M & P & A & L & H & S & M & R & L & V & A & Q & V & L & T & L & S\end{array}$

181 GCAAGGTGGCGCAACGCCATGCGGCTGACCATCAACCCCAGCGAGCTGTCTGTCGCCAGCCTGCCCGACAGCACCACAGGCTGCGAGCAC $\begin{array}{llllllllllllllllllllllllllllllllllll}G & K & V & A & Q & R & H & A & A & D & H & Q & P & Q & R & A & V & C & R & Q & P & A & R & Q & H & H & R & L & R & A\end{array}$

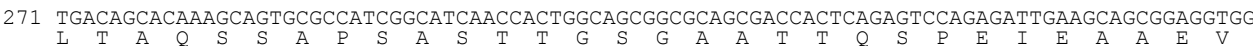

361 AGGCAGCAGCAGCAGACGCACGTCAAAATGGCTCGCCTTCTTTCTCAAATATGAAGGTGTATGGGTTGCAAGAGGAGAACTGGGAGAAGG

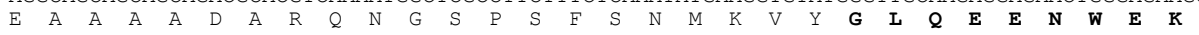

451 CTGCACTGAGCATCGTGGTGGTGGGCGCGTCTGGTGACCTGGCCAAGAAGAAAATCTTCCCCTCCCTCTTTGCGCTGTACTATGAAAACA $\begin{array}{llllllllllllllllllllllllllllll}\mathbf{A} & \mathbf{A} & \mathrm{L} & \mathbf{S} & \mathbf{I} & \mathbf{V} & \mathrm{V} & \mathrm{V} & \mathrm{G} & \mathrm{A} & \mathrm{S} & \mathrm{G} & \mathrm{D} & \mathrm{L} & \mathrm{A} & \mathrm{K} & \mathrm{K} & \mathrm{K} & \mathrm{I} & \mathrm{F} & \mathrm{P} & \mathrm{S} & \mathrm{L} & \mathrm{F} & \mathrm{A} & \mathrm{L} & \mathrm{Y} & \mathrm{Y} & \mathrm{E} & \mathrm{N}\end{array}$

541 TGCTTCCGCAGAACTTCAAGGTGTATGGCTACGCCCGCAGCAAGATGAACGACGAGGAGTTCCGAGACCTGATTGCCGGCAGCCTGACCT

631 GCAGGCTGAACGACGCTGGTGACTGCGGCAAGAAGATGGACGAGTTCCTGGAGCGCTGCTTCTACCAGGCGGGCCAGTACGCATCTGAGG

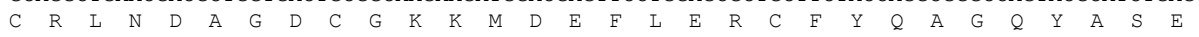

721 ACGACTTTGCGGCGCTGGACAAGCGCATGGCTGACGGGGAGAGCGAGCAGTCCTGCGCAGACAGAATGTTCTACCTCTCGATCCCGCCAA $\begin{array}{llllllllllllllllllllllllllllllll}D & D & F & A & A & L & D & K & R & M & A & D & G & E & S & E & Q & S & C & A & D & R & M & F & Y & L & S & I & P & P\end{array}$

811 ACATCTTCACCACGGTGGCAGCCTGCGCCTCCAAGGCAGCATCCAGCAAGTGTGGCTGGACGCGCATGATTGTTGAGAAGCCGTTTGGCA $\begin{array}{lllllllllllllllllllllllllllllllll}N & I & F & T & T & V & A & A & C & A & S & K & A & A & S & S & K & C & G & W & T & R & M & I & V & E & K & P & L & G\end{array}$

901 AGGACAGCGAGTCGTTCCAGGAGTTGAGCGCTGCGCTGTACGAGCACCTTCGAGAGGACCAGATATACCGCATTGACCACTACCTGGGCA $\begin{array}{llllllllllllllllllllllllllllllllll}K & D & S & E & S & F & Q & E & L & S & A & A & L & Y & E & H & L & R & E & D & Q & I & Y & R & I & D & H & Y & L & G\end{array}$

991 AGGAGCTGATCGAGAACCTGACGGTGCTGCGCTTTGCAAACCTGGTGTTTGAGCCGCTGTGGAGCAGGCAGTACATCAGAAACGTGCAGG $\begin{array}{lllllllllllllllllllllllllllllll}K & E & L & I & E & N & L & T & V & L & R & F & A & N & L & V & F & E & P & L & W & S & R & Q & Y & I & R & N & V & Q\end{array}$

1081 TCATCTTCAGCGAGAACTTTGGGACAGAGGGCCGAGGGGGCTACTTTGACCAGTACGGCATTGTGAGGGACGTCATCCAAAACCACCTGC

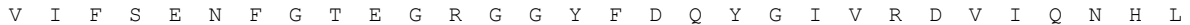

171 TCCAAATACTGGCCCTCTTCGCCATGGAGCAGCCGGCCAGCCTGGATGCCGAGGACATTCGTAACGAGAAGGTCAAGGTGCTGAAGAGCA $\begin{array}{llllllllllllllllllllllllllllllllllll}L & Q & I & L & A & L & F & A & M & E & Q & P & A & S & L & D & A & E & D & I & R & N & E & K & V & K & V & L & K & S\end{array}$

1261 TGGGCCAGGTGCGGCTGGAGGACATGGTGTTGGGGCAGTACCGCTCACGCACCACACGCGGGACCACGCTGCCAGGATACCTGGACGACG $\begin{array}{llllllllllllllllllllllllllllllllll}M & G & Q & V & R & L & E & D & M & V & L & G & Q & Y & R & S & R & T & T & R & G & T & T & L & P & G & Y & L & D & D\end{array}$

1351 ACACGGTACCGCCAAACAGCATCACCCCCACCTTTGCCGCCTGCTCCGTGTTCATCAACAATGCCAGGTGGGACGGCGTGCCCTTCCTGC $\begin{array}{lllllllllllllllllllllllllllllllll}D & T & V & P & P & N & S & I & T & P & T & F & A & A & C & S & V & F & I & N & N & A & R & W & D & G & V & P & F & L\end{array}$

1441 TCAAGGCGGGCAAGGCGCTGGCCAACAAGGCGGCCGAGATCCGGGTGCAGTTCCGGCATGTGCCGGGCAACCTGTACCGCAACAAACTGG $\begin{array}{lllllllllllllllllllllllllllllllllllll}L & K & A & G & K & A & L & A & N & K & A & A & E & I & R & V & Q & F & R & H & V & P & G & N & L & Y & R & N & K & L\end{array}$

1531 GGCTGGACCTGGACAAGGCCACCAACGAGCTGGTCATCCGCGTCCAGCCCAACGAGGGCATCTACCTGAAAGTGAACAACAAGGTGCCGG $\begin{array}{llllllllllllllllllllllllllllllll}G & L & D & L & D & K & A & T & N & K & \text { L } & \text { V } & \text { I } & \mathbf{R} & \mathbf{V} & \mathbf{Q} & \mathbf{P} & \mathbf{N} & \mathbf{E} & \mathbf{G} & \mathbf{I} & \mathbf{Y} & \mathbf{L} & \mathbf{K} & \mathbf{V} & \mathbf{N} & \mathbf{N} & \mathbf{K} & \mathbf{V} & \mathbf{P}\end{array}$

1621 GGCTGGGCCTGCGCATAGACACAACGCGCCTCGACCTCACCTACAAGTCCAAGTACCAGGCAACACTGCCAGATGCATATGAGCGGCTGA $\begin{array}{llllllllllllllllllllllllllllllll}G & L & G & L & R & I & D & T & T & R & L & D & L & T & Y & K & S & K & Y & Q & A & T & L & P & D & A & Y & E & R & L\end{array}$ 1711 TCCTGGACTGCATCAACGGCGACCGCCGCCTGTTCATCCGCAACGACGAGCTGGAGGTGGCCTGGGAGAAGTTCACTCCGGTGCTCAAGG $\begin{array}{llllllllllllllllllllllllllllllllll}I & L & D & C & I & N & G & D & R & R & L & F & I & R & N & D & E & L & E & V & A & W & E & K & F & T & P & V & L & K\end{array}$ 1801 AGATTGAGGATCGGGGTGTGCAGCCGGAGCTGTACCCCTACGGCAGCCGCGGCCCCGTTGGCGCGCACTACCTGGCAGCCAAGCACGGCG $\begin{array}{lllllllllllllllllllllllllllllllll} & E & I & E & D & R & G & V & Q & P & E & L & Y & P & Y & G & S & R & G & P & V & G & A & H & Y & L & A & A & K & H & G\end{array}$

1891 TGCGGTGGGGGGACCTGGCCGCTGACGACGAGTGAGCCGCCCGCCTGGCTGGCAACACAAGCTGCCTGCCAGTCCATTGTCCACAAACCC $\begin{array}{lllllllllllllllllll}V & R & W & G & D & L & A & A & D & D & E & *\end{array}$

1981 CGTCCCTCCTCCTCCAACAACTTGACCTCTACGCCTCCGGCTGGCATGCCACGCAACTTCATTTCGCAGCCGCCCTTTGAACGACGCCCC

2071 ATCCAAGGCATAAACTGTCACGGCTATCGCCACACTGCTGGCCGGATGCCCCGTCAGCGCCCGGCTGCCGCAGCGGTTGGCACACCCACG

2161 TCCTGTACACCACACTACACATACCTCCTCTGCCTTCCTTCACCCTGTTTAGCTGCTGTTTAGGTGCTGCTGCTGCACTTTTGGTTGCCC

2251 CCACTGCGCATGGTGCAGCGGGTCACCAGCACAGGCCACACACACCCTGTGACCTTGTCACCGCTGTTCTGTCCCTCTCTCGCCCCTAGC

2341 TGACCCTAGCTGACACCATGTCACCAACCCATGTCCCCTGTAATTGCTGTTGCCTGG

Fig. 1. Nucleotide and deduced amino acid sequences of the cDNA of $C v c h G 6 P D H$ are shown. The putative active site (-RIDHYLGKE-) of G6PDH is double-underlined and two NADP-binding sites (-GXXGXXG/A-) are boxed. The two regions that were identical to the internal amino acid sequences of purified G6PDH $\mathrm{PHonjoh}_{2}$ et al., 2003) are shown in bold letters. Two conserved cysteine residues found in common plastidic G6PDH are circled.

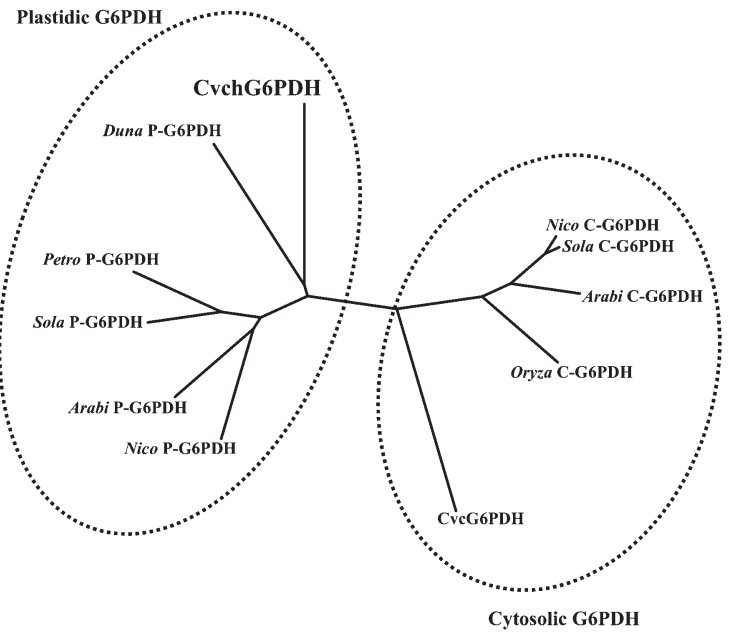

Fig. 2. Phylogenetic tree of G6PDHs was constructed with the Neighbor-Joining method using the clustal W program. Accession numbers for the sequences are shown in parentheses as follows: Duna P-G6PDH: Dunaliella bioclata plastidic G6PDH (AJ132346), Petro P-G6PDH: Petroselinum crispum plastidic G6PDH (AF012861), Sola P-G6PDH: Solanim tuberosum plastidic G6PDH (AJ010712), Arabi P-G6PDH: Arabidopsis thaliana plastidic G6PDH (AJ001770), Nico C-G6PDH: Nicotiana tabacum cytosolic G6PDH (AJ001770), Sola C-G6PDH: S. tuberosum cytosolic G6PDH (X74421), Arabi C-G6PDH: Arabidopsis thaliana cytosolic G6PDH (AJ010971), CvcG6PDH: Chlorella vulgaris C-27 cytosolic G6PDH (AB085846). 
of $C v c h G 6 P D H$ cDNA, and thus the DNA region encoding mature CvchG6PDH ( $m$ CvchG6PDH) was determined. The length of $m C v c h G 6 P D H$ was $1,500 \mathrm{bp}$ in length and it encoded 500 amino acid residues with a predicted molecular mass of about $56.6 \mathrm{kDa}$ and an isoelectric point of 5.35. The region containing 98 amino acids from N-terminus of CvchG6PDH was determined as a transit peptide region. Based on the results, CvchG6PDH was suggested to encode the chloroplastic isoform of the enzyme. The nucleotide sequence of the cloned CvchG6PDH cDNA was deposited at DDBJ/ EMBL/GenBank under accession number AB331729.

\section{Expression of $m C v c h G 6 P D H$ in $E$. coli and G6PDH assays of the expressed protein}

To confirm that the protein encoded by $m C v c h$ $G 6 P D H$ is functionally active, the gene was introduced into $E$. coli using a pET-17xb vector. According to the result of SDS-PAGE, the mCvchG6PDH (56.9 kDa) protein was expressed as a soluble protein when treated with IPTG at $25^{\circ} \mathrm{C}$ (Fig. 3A). G6PDH activity and DTTsensitivity of the mCvchG6PDH was examined. An extract of E. coli expressing CvcG6PDH (Honjoh et al., 2007) was also prepared to compare DTT-sensitivity of CvcG6PDH with that of mCvchG6PDH. The mCvch-
G6PDH protein showed remarkably high G6PDH activity (Table 2), and its activity was inhibited in the presence of DTT, while the activity of CvcG6PDH was not inhibited with DTT (Fig. 3B).

\section{Expression and purification of His-tagged mCvch- G6PDH}

To produce anti-mCvchG6PDH antibodies, $m C v c h-$ $G 6 P D H$ gene was expressed in E. coli as a His-tagged protein. E. coli cells expressing the gene were cultured at $25^{\circ} \mathrm{C}$ for $6 \mathrm{~h}$ after addition of $1 \mathrm{mM}$ IPTG. Expression, purification, and removal of His-tag region of His-tagged mCvchG6PDH protein were confirmed by SDS-PAGE

Table 2. Specific activity of enzyme extracts of $E$. coli transformed with $\mathrm{pET}-17 \mathrm{xb} / C v c G 6 P D H$ and $\mathrm{pET}-17 \mathrm{xb} /$ $m$ Cvch G6PDH

\begin{tabular}{lc}
\hline \multicolumn{1}{c}{ Plasmid } & Specific activity (U/mg protein) \\
\hline pET-17xb & Not detected \\
pET-17xb/CvcG6PDH & $19.9 \pm 2.7$ \\
pET-17xb/mCvchG6PDH & $51.0 \pm 2.5$ \\
\hline
\end{tabular}

Values are means \pm SD obtained from three independent experiments.
A

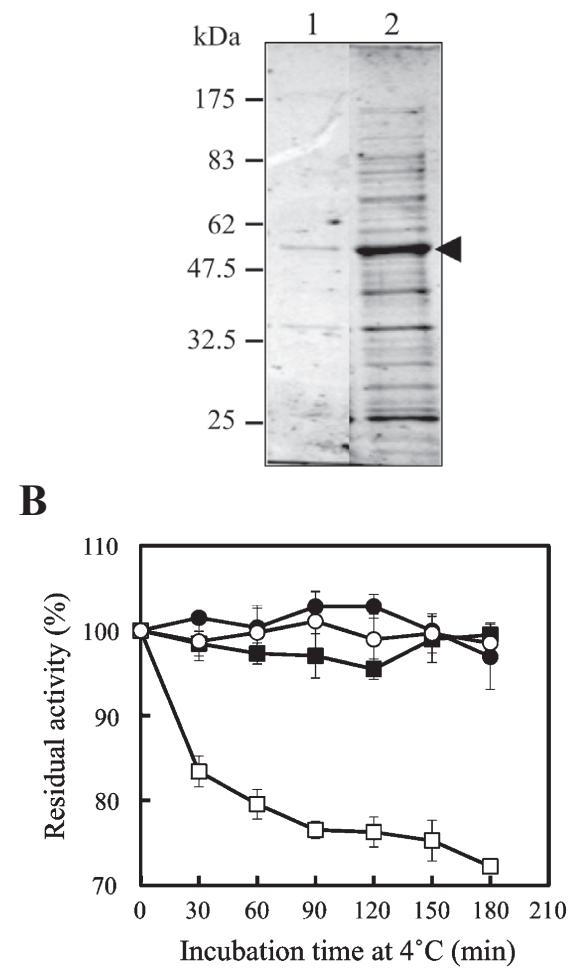

C

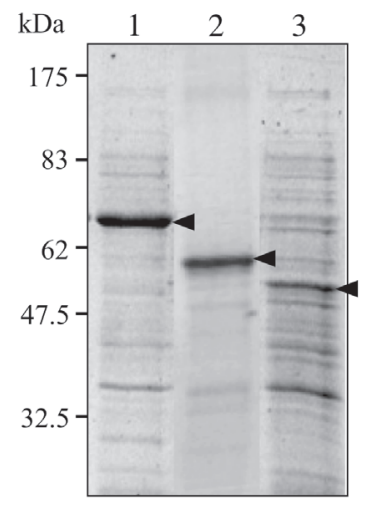

Fig. 3. (A) The $m C v c h G 6 P D H$ was expressed in $E$. coli with a pET-17xb vector. Lane 1 , insoluble protein; lane 2, soluble protein from the transformed $E$. coli. (B) DTT sensitivity of mCvchG6PDH was examined using $E$. coli crude extract. Closed symbols: incubation without DTT; ( C) CvcG6PDH; (ם) mCvchG6PDH. Open symbols: incubation with 100 mM DTT; ( $)$ CvcG6PDH; ( $\square$ ) mCvchG$6 \mathrm{PDH}$. All values are means $\pm \mathrm{SD}$ obtained from three independent experiments. (C) The $m C v c h$ $G 6 P D H$ was expressed in $E$. coli as a His-tagged protein with a pET-32a(+) vector to purify the expressed protein. Lane 1, purified His-mCvchG6PDH by $\mathrm{Ni}^{2+}$-affinity chromatography; lane 2 , His-mCvchG6PDH digested with thrombin; His-mCvchG6PDH digested with enterokinase. The arrowheads indicate the bands of the target proteins in each figure. 
(Fig. 3C). The N-terminal sequence of the purified protein was determined as $\mathrm{NH}_{2}$-AMADIGSGLQEENWEK (tagging peptide region was underlined), and the sequence without an underline was identical to the $\mathrm{N}$-terminal sequence of $\mathrm{G} \mathrm{PDH}_{2}$ identified previously (Honjoh et al., 2003). Then, antibodies against mCvchG6PDH were raised using the purified protein as an antigen.

\section{Change in the expression pattern of $\operatorname{CvchG6PDH}$ during hardening}

Northern blot analysis of CvchG6PDH gene was performed using total RNAs isolated from 0, 3, 9, and 24-h hardened Chlorella cells. The transcription of CvchG6PDH increased up to 3-h hardening and the high level of transcription continued thereafter (Fig. 4A).

Western blot analysis was performed using protein extracts of cells hardened for $0,3,9$, and $24 \mathrm{~h}$ to investigate change in the CvchG6PDH protein amount in cells during hardening. CvchG6PDH protein was detected with anti-mCvchG6PDH antibodies. The protein amount of CvchG6PDH decreased at the early phase of hardening and then increased, but it did not show dramatic change in the amount (Fig. 4B).

$\mathbf{A}$

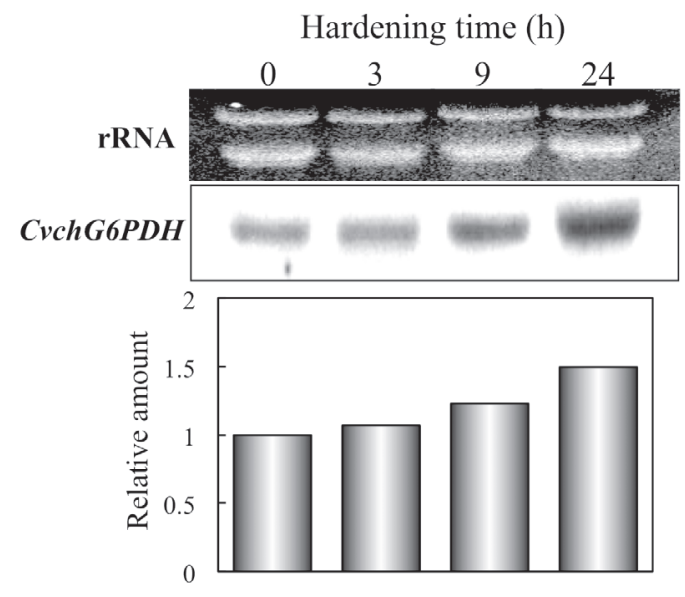

B

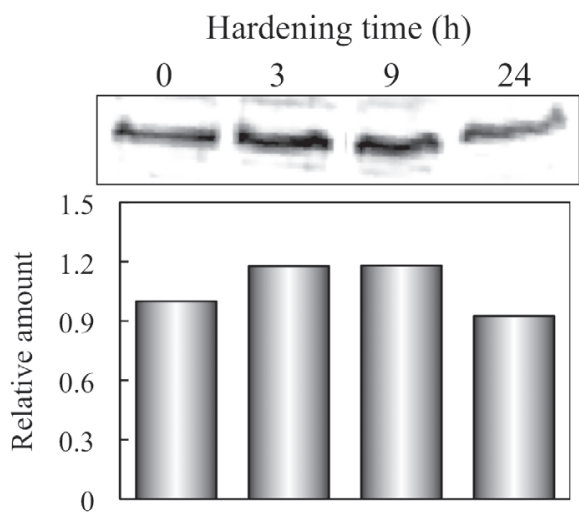

Fig. 4. Hardening-induced change in the expression level of CvchG6PDH in Chlorella cells was investigated at (A) the transcriptional and (B) the translational levels.

\section{Expression of the $m \boldsymbol{C v c h} G 6 P D H$ in yeast}

The $m C v c h G 6 P D H$ was expressed in yeast with a pTG887 vector. Expression of the genes was confirmed by enzyme assays (Table 3). Specific activity of the extract of INVSc2/pTG887/mCvchG6PDH (4.58 $0.37 \mathrm{U} /$ mg protein) was remarkably higher than those of control yeast (INVSc2/pTG887; 0.28 $\pm 0.01 \mathrm{U} / \mathrm{mg}$ protein) and

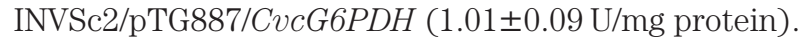

Table 3. Specific activity of enzyme extracts of yeast transformants expressing $C v c G 6 P D H$ and $m C v c h G 6 P D H$

\begin{tabular}{lc}
\hline \multicolumn{1}{c}{ Plasmid } & Specific activity (U/mg protein) \\
\hline pTG887 (control) & $0.28 \pm 0.01$ \\
pTG887/CvcG6PDH & $1.01 \pm 0.09^{*}$ \\
pTG887/mCvchG6PDH & $4.58 \pm 0.37^{* *}$ \\
\hline
\end{tabular}

Values are means \pm SD obtained from three independent experiments. Significance against the value of control yeast is indicated as: $* p<0.05 ; * * p<0.01$.

A

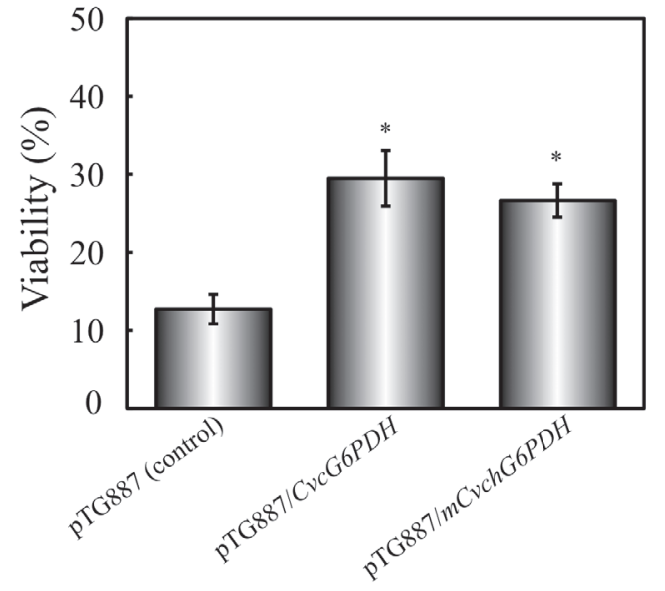

B

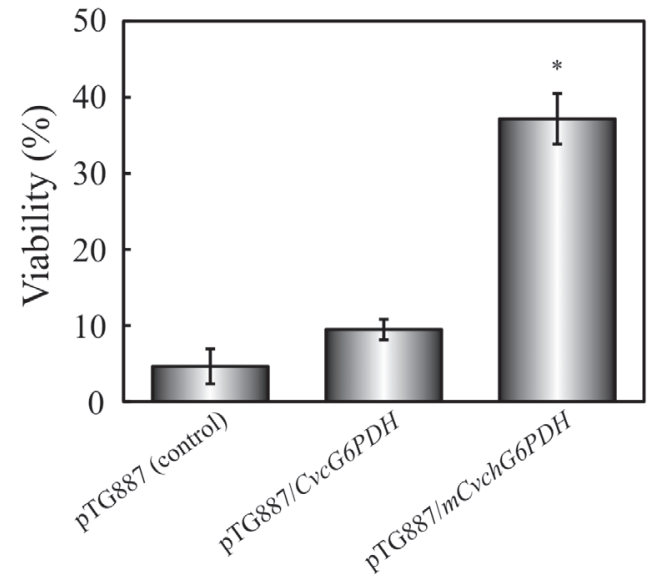

Fig. 5. (A) Freezing and (B) menadione-induced oxidative stress tolerances of yeast expressing Chlorella G6PDH genes. Values are means \pm SD obtained from three independent experiments. Significance against the value of control yeast is indicated as: $* p<0.01$. 


\section{Stress tolerances of the transformed yeast}

Effects of mCvchG6PDH on freezing and oxidative stress tolerances were investigated using $S$. cerevisiae INVSc2 as a model eukaryote. As shown in Fig. 5A, the viability of INVSc2/pTG887/mCvchG6PDH (26.7 $\pm 2.2 \%)$ after freezing and thawing was significantly higher than those of control yeast $(12.7 \pm 1.9 \%)$, while it was slightly lower than that of INVSc2/pTG887/CvcG6PDH $(29.5 \pm 3.6 \%)$.

Oxidative stress treatment was performed using menadione as an intracellular ROS generator. As shown in Fig. 5B, the viability of INVSc2/pTG887/mCvch $G 6 P D H$ $(37.17 \pm 3.33 \%)$ after $1-\mathrm{h}$ incubation with $200 \mu \mathrm{M}$ menadione was significantly higher than those of control yeast $(4.64 \pm 2.30 \%) \quad$ and INVSc2/pTG887/CvcG6PDH $(9.47 \pm 1.35 \%)$.

\section{DISCUSSION}

$\mathrm{G} 6 \mathrm{PDH}$ is a key-enzyme of the pentose phosphate pathway (Wendt et al., 2000). C. vulgaris C-27 cells acquire freezing tolerance after cold-hardening, at which the G6PDH activity increased approximately 1.5-fold (Sadakane et al., 1980). Two types of G6PDH isozymes, which were predicted as cytosolic and chloroplastic G6PDHs, were identified in C. vulgaris C-27 and characterized previously (Honjoh et al., 2003). In the present study, we isolated a full-length cDNA clone encoding the chloroplastic isoform, and investigated its involvement and function in freezing tolerance.

A characteristic feature of chloroplastic G6PDH is considered as inactivation by covalent redox modification mediated by the ferredoxin-thioredoxin system (Scheibe, 1990; Buchanan, 1991) or DTT (Honjoh et al., 2003), and this inactivation is due to the reduction of two cysteine residues specific to chloroplastic G6PDH (Wendt et al., 1999). The cysteine residues were also observed in the deduced amino acid sequence of CvchG6PDH as shown in Fig. 1. G6PDH activity in crude extract of $E$. coli expressing $m C v c h G 6 P D H$ was suppressed when the extract was treated with DTT, while that of E. coli expressing CvcG6PDH did not show DTT-sensitivity (Fig. 3B). Our results suggested that the CvchG6PDH cDNA isolated in the present study encoded chloroplastic G6PDH in C. vulgaris C-27.

The CvchG6PDH protein amount in $C$. vulgaris C-27 did not show similar change to the up-regulation of the total G6PDH activity during hardening (Fig. 4B), although the transcript level of CvchG6PDH increased after $3-\mathrm{h}$ hardening and was kept at a high level throughout 24-h hardening (Fig. 4A). Our previous study showed the change in CvcG6PDH activity during hardening did not reflect the hardening-induced increase in the total G6PDH activity (Honjoh et al., 2007). Those results on expression changes in CvcG6PDH and CvchG6PDH were not sufficient to explain the increase in G6PDH activity of $C$. vulgaris C-27 during hardening. Several higher plants have several genes encoding G6PDH, for example, Arabidopsis has two genes encoding cytosolic G6PDH and four genes encoding plastidic G6PDH (Wakao and
Benning, 2005), and tobacco has two genes encoding cytosolic G6PDH and two genes encoding plastidic G6PDH (Wendt et al., 1999). To clarify the involvement of $\mathrm{G} 6 \mathrm{PDH}$ in the acquisition of freezing tolerance of Chlorella, further isotypes of G6PDH should be searched for and isolated.

The mCvchG6PDH improved freezing tolerance of yeast significantly, and the improvement of freezing tolerance was also observed in yeast expressing $C v c G 6 P D H$ (Fig. 5A). Since there was no significant difference between freezing tolerances of $C v c G 6 P D H-$ and $m C v c h$ $G 6 P D H$-expressing yeasts, the observed effect was considered as common effect of G6PDH isozymes. One of the roles of G6PDH in the acquisition of freezing tolerance is perhaps due to the production of a reducing equivalent NADPH, which serves as an activator of several antioxidant enzymes, such as glutathione reductase, thioredoxin reductase (Carmel-Harel and Storz, 2000), monodehydroascorbate reductase (Foyer et al., 1994), and catalase (Salvemini et al., 1999). Those reports suggest that G6PDH is involved in the acquisition of freezing tolerance by activating antioxidant enzymes that can play a role in the acquisition of freezing tolerance. Freezing-thawing process can generate oxidative stress such as production of reactive oxygen species $\left(\mathrm{O}_{2}^{-}, \mathrm{H}_{2} \mathrm{O}_{2}\right.$, $\mathrm{OH} \cdot)$, reactive nitrogen species $\left(\mathrm{NO}, \mathrm{ONOO}^{-}\right)$, and lipid peroxides (Carmel-Harel and Storz, 2000; Xin and Browse, 2000; Chatterjee and Gagnon, 2001; Mittler, 2002; Neil et al., 2002). Since the target peroxides of the antioxidant enzymes vary, the activities of such enzymes and the resulting products should be investigated to clarify the function of $\mathrm{G} 6 \mathrm{PDH}$ in the acquisition of freezing tolerance of Chlorella.

The mCvchG6PDH also improved menadioneinduced oxidative stress tolerance of yeast, while the improvement was not significant in CvcG6PDHexpressing yeast (Fig. 5B). McAims et al. (2003) have demonstrated that menadione inactivated G6PDH activity when tested using bovine endothelial cells, causing decrease in cellular antioxidant capacity. Thus, the intrinsic G6PDH activity of yeast might be suppressed due to such function of menadione in our studies, and the introduced Chlorella G6PDHs may enhance G6PDH activity in yeast cells to maintain cellular reactions under such unfavorable condition in which G6PDH activity was inhibited. Based on the consideration, the difference between the viabilities of the CvcG6PDH- and mCvchG6PDHexpressing strains (Fig. 5B) is perhaps due to the difference between their G6PDH activities (Table 3). Although we could not find any specific function of CvchG6PDH under stress condition, the contribution of enhanced G6PDH activity to alleviation of cellular damages induced by menadione was first identified in the present study. The effect would be important to survive under freezingthawing stress since the stress is accompanied by several types of oxidative stress as mentioned above. Our data suggest that the one of the functions of G6PDH in the acquisition of freezing tolerance of Chlorella is to alleviate oxidative stress generated under low-temperature and freezing-thawing processes. 


\section{ACKNOWLEDGMENTS}

The authors are grateful to Dr. M. Nakao of Kyushu University for amino acid sequencing. We also thank to Transgene S. A. for use of the pTG887 plasmid and to Mr. Hsu-Ming Wen for preparation of the manuscript.

\section{REFERENCES}

Altschul, S. F., T. L. Madden, A. A. Schäffer, J. Zhang, Z. Zhang, W. Miller and D. J. Lipman 1997 Gapped BLAST and PSIBLAST: a new generation of protein database search programs. Nucleic Acids Res., 25: 3389-3402

Buchanan, B. B. 1991 Regulation of CO2 assimilation in oxygenic photosynthesis: the ferredoxin/thioredoxin system. Arch. Biochem. Biophys., 288: 1-9

Carmel-Harel, O. and G. Storz 2000 Roles of the glutathioneand thioredoxin-dependent reduction systems in the Escherichia coli and Saccharomyces cerevisiae responses to oxidative stress. Annu. Rev. Microbiol., 54: 439-461

Chatterjee, S. and C. Gagnon 2001 Production of reactive oxygen species by spermatozoa undergoing cooling, freezing, and thawing. Mol. Reprod. Dev., 59: 451-458

Cosgrove, M. S., C. Naylor, S. Paludan, M. J. Adams and H. R. Levy 1998 On the mechanism of the reaction catalyzed by glucose 6-phosphate dehydrogenase. Biochemistry, 37: 2759-2767

Debnam, P. M., A. R. Fernie, A. Leisse, A. Golding, C. G. Bowsher, C. Grimshaw, J. S. Knight and M. J. Emes 2004 Altered activity of the P2 isoform of plastidic glucose 6-phosphate dehydrogenase in tobacco (Nicotiana tabacum cv. Samsun) causes changes in carbohydrate metabolism and response to oxidative stress in leaves. Plant J., 38: 49-59

Esposito, S., E. Carillo and S. Carfagna 1998 Ammonium metabolism stimulation of glucose-6P dehydrogenase and phosphoenolpyruvate carboxylase in young barley roots. $J$. Plant Physiol., 153: 61-66

Foyer, C. H., M. Lelandais and K. J. Kunert 1994 Photooxidative stress in plants. Physiol. Plant., 92: 696-717

Hatano, S., H. Sadakane, M. Tutumi and T. Watanabe 1976 Studies on frost hardiness in Chlorella ellipsoidea II. Effects of inhibitors of RNA and protein synthesis and surfactants on the process of hardening. Plant Cell Physiol., 17: 643-651

Hauschild, R. and A. von Schaewen 2003 Differential regulation of glucose-6-phosphate dehydrogenase isoenzyme activities in potato. Plant Physiol., 133: 47-62

Honjoh, K., A. Mimura, E. Kuroiwa, T. Hagisako, K. Suga, H. Shimizu, R. S. Dubey, T. Miyamoto, S. Hatano and M. Iio 2003 Purification and characterization of two isoforms of glucose 6-phosphate dehydrogenase (G6PDH) from Chlorella vulgaris C-27. Biosci. Biotechnol. Biochem., 67: 1888-1896

Honjoh, K., T. Machida, T. Hagisako, K. Suga, M. Yonekura, H. Shimizu, N. Ohashi, T. Miyamoto, S. Hatano and M. Iio 2007 Molecular cloning and characterization of a cDNA for lowtemperature-inducible cytosolic glucose 6-phosphate dehydrogenase gene from Chlorella vulgaris and expression of the gene in Saccharomyces cerevisiae. Plant Sci., 172: $649-658$

Houton, P., K.-J. Park, T. Obayashi and K. Nakai 2006 "Protein subcellular localization prediction with WoLF PSORT". Proceedings of Asian Pacific Bioinformatics Conference, APBC06: $39-48$

Ito, H., Y. Fukuda, K. Murata and A. Kimura 1983 Transformation of intact yeast cells treated with alkali cations. J. Bacteriol., 153: $163-168$

Kocsy, G., G. Galiba and C. Brunold 2001 Role of glutathione in adaptation and signaling during chilling and cold acclimation in plants. Physiol. Plant., 113: 158-164

Laemmli, U. K. 1970 Cleavage of structural proteins during the assembly of the head of bacteriophage $\mathrm{T}_{4}$. Nature, 227: 680 685
Levitt, J. 1980 Chilling, freezing and high temperature stresses, In "Responses of Plants to Environmental Stresses" Vol. 1, 2nd ed., Academic Press, New York, pp. 27-64

Machida, T., E. Kato, A. Ishibashi, J. Sato, S. Kawasaki, Y. Niimura, K. Honjoh and T. Miyamoto 2009 Expression pattern of a chloroplast NADPH-dependent thioredoxin reductase in Chlorella vulgaris during hardening and its interaction with 2-Cys peroxiredoxin. Biosci. Biotechnol. Biochem., 73: 695701

McAims, W. C., R. C. Schaeffer Jr, J. W. Baynes and M. B. Wolf 2003 Menadione causes endothelial barrier failure by a direct effect on intracellular thiols, independent of reactive oxydant production. Biochim. Biophys. Acta, 1641: 43-53

Mittler, R. 2002 Oxidative stress, antioxidants and stress tolerance. Trends Plant Sci., 7: 405-410

Neil, S., R. Desikan and J. Hancock 2002 Hydrogen peroxide signaling. Curr. Opin. Plant Biol., 5: 388-395

Nemoto, Y. and T. Sasakuma 2000 Specific expression of glucose-6-phosphate dehydrogenase (G6PDH) gene by salt stress in wheat (Triticum aestivum L.). Plant Sci., 158 $53-60$

Sadakane, H., K. Kabata, K. Ishibashi, T. Watanabe, and S. Hatano 1980 Studies on frost hardiness in Chlorella ellipsoidea. V. The role of glucose and related compounds. Environ. Exp. Bot., 20: 297-305

Salvemini, F., A. Franze, A. Iervolino, S. Filosa, S. Salzamo and M. V. Ursini 1999 Enhanced glutathione levels and oxidoresistance mediated by increased glucose-6-phosphate dehydrogenase expression. J. Biol. Chem., 274: 2750-2757

Sanger, F., S. Nicklen and A. R. Coulson 1977 DNA sequencing with chain-terminating inhibitions. Proc. Natl. Acad. Sci. USA, 74: 403-410

Sarhan, F. and M. Perras 1987 Accumulation of high molecular weight protein during cold hardening of wheat (Triticum aestivum L.). Plant Cell Physiol., 28: 1173-1179

Scheibe, R. 1990 Light/dark modulation: regulation of chloroplast metabolism in a new light. Bot. Acta., 103: 327-334

Schnarrenberger, C., A. Oeser and N. E. Tolbert 1973 Two isoenzymes each of glucose-6-phosphate dehydrogenase in spinach leaves. Arch. Biochem. Biophys., 154: 438-448

Seppanen, M. M. and K. Fagerstedt 2000 The role of superoxide dismutase activity in response to cold acclimation in potato. Physiol. Plant., 108: 279-285

Tao, D. L., Y. H. Jin and Y. J. Du 1990 PSII electron transport and superoxide dismutase of Korean pine during winter. Sci. Silvae. Sin., 26: 289-293

Tao, D. L., Y. H. Jin, Y. J. Du, Y. Y. Liu, G. Z. Liu and R. Y. Zhan 1992 Responses of organic free-radicals production of overwintering conifer needles to low temperature and light. Chin. J. Appl. Ecol., 3: 120-124

Tao, D. L., D. Oquist and D. Wingsle 1998 Active oxygen scavengers during cold acclimation of scots pine seedlings in relation to freezing tolerance. Cryobiology, 37: 38-45

Thomashow, M. F. Molecular genetics of cold acclimation of higher plants. Adv. Genet., 28: 99-131

Towbin, H., T. Staehelin and J. Gordon 1979 Electrophoretic transfer of proteins from polyacrylamide gels to nitrocellulose sheets: Procedure and some applications. Proc. Natl. Acad. Sci. USA, 76: 4350-4354

Uemura, M., R. A. Joseph and P. L. Steponkus 1995 Cold acclimation of Arabidopsis thaliana. Plant Physiol., 109: 15-30

Wakao, S. and C. Benning 2005 Genome-wide analysis of glucose-6-phosphate dehydrogenases in Arabidopsis. Plant J., 41: $243-256$

Wenderoth, I., R. Scheibe and A. von Schaewen 1997 Identification of the cysteine residues involved in redox modification of plant plastidic glucose-6-phosphate dehydrogenase. J. Biol. Chem., 272: 26985-26990

Wendt, U. K., R. Hauschild, C. Lange, M. Pietersma, I. Wenderoth and A. von Schaewen 1999 Evidence for functional convergence of redox regulation in G6PDH isoforms of cyanobacteria and higher plants. Plant Mol. Biol., 40: 487-494 
Wendt, U. K., I. Wenderoth, A. Tegeler and A. von Schaewen 2000 Molecular characterization of a novel glucose-6-phosphate dehydrogenase from potato (Solanum tuberosum L.). Plant J., 23: 723-733

Xin, Z. and J. Browse 2000 Cold comfort farm: the acclimation of plants to freezing temperatures. Plant Cell Environ., 23: 893-902
Yanai, H. 2002 Statcel- The useful add-in software forms on Excel (2nd ed), OMS, Tokyo, Japan

Yang, S. H., L. J. Wang and S. H. Li 2007 Ultraviolet-B irradiation-induced freezing tolerance in relation to antioxidant system in winter wheat (Triticum aestivum L.) leaves. Environ. Exp. Bot., 60: 300-307 